\title{
Immunopathology of CMV Co-infection: review
}

\begin{abstract}
CMV is a common complex viral infection that affects patients at all ages, especially newborns. It causes a lifelong infection with a frequency of approximately $80 \%$ of the population will become infected by age 40. Most CMV infection is silent infection (no symptoms), however, in immunocompromised individuals, a symptomatic infection persists with few medical treatments or vaccine currently available. Co-infection of CMV with other viruses had drawn much attention in the last decade, as diagnostic methodologies became more reliable, and many cases have been reported. The long-term relationships between immune responses, viral load, and most importantly, disease progression in those who are persistently infected with CMV are still poorly understood. This review will summarize the current knowledge of the immunopathological features of different CMV co-infections and highlight the importance of considering CMV co-infection in the patient treatment and management.
\end{abstract}

Keywords: immunopathology, cmv, infection, co-infection
Volume I Issue 3 - 2014

\author{
Alaa Ahmed \\ Faculty of Public Health \& Tropical Medicine, Jazan University, \\ Saudi Arabia \\ Correspondence: Alaa Ahmed, Immunopathology and \\ Laboratory Medicine, Medical Research Center/ Faculty of \\ Public Health \& Tropical Medicine, Jazan University, Saudi Arabia, \\ Email Alaa-ahmed@msn.com
}

Received: June 05, 2014 | Published: August 06, 2014
Abbreviations: CMV, cytomegalovirus; TNF, tumor necrosis factor; RSV, respiratory syncytial virus; $\mathrm{CP}$, chlamydia pneumonia; HSV, herpes simplex virus

\section{Introduction}

Cytomegalovirus (CMV) is the most prevalent viral diseases globally, ${ }^{1}$ with an estimated positive infection rate of $80 \%$ to $90 \%$ of the US population., ${ }^{2,3} \mathrm{CMV}$ is a ubiquitous DNA virus belongs to the $\beta$-herpes virus family that causes severe disease with high morbidity and mortality in immunocompromised patients, and is the predominant infectious cause of congenital birth defects. ${ }^{4,5}$ Most patients are infected early in life, which results in a lifelong latent infection. ${ }^{5}$ The immune system can tolerate the viral infection but cannot eradicate the virus. ${ }^{6}$ The public health annual burden in the US alone for CMV infection and co-infection was estimated to exceed $\$ 4.4$ billion. $^{7} \mathrm{CMV}$ shedding is persistent during the latent infection in multiple body fluids (blood, saliva, tears, urine, genital secretions, and breast milk). Active CMV replication and to some extent gene expression ${ }^{8}$ occurs continuously as indicated by the frequency of CMV shedding, ${ }^{9}$ kinetics of reactivation after transplantation (immune suppression), ${ }^{10}$ and the $\mathrm{CMV}$-specific T cell response. ${ }^{11,12}$ The persistent CMV latent infection together with the frequent immune system stimulation, which leads to a low grade inflammatory response may contribute or involved in the development of chronic diseases, such as atherosclerosis, restenosis and transplant vascular sclerosis. ${ }^{13} \mathrm{CMV}$ is genetically diverse large virus with more than 200 open reading frame producing effector proteins, ${ }^{14}$ of which, onequarter is committed to replication. ${ }^{15,16}$ Hence, the majority of viral proteins may potentially alter the host cellular responses; of all herpes viruses, CMV expresses the most genes that alter innate and adaptive host immune responses. ${ }^{17}$ Several regions of the CMV genome are used to genotype the virus based on clustering of polymorphism. Frequently, mixed infection with multiple CMV strains occurs in various patient populations including both immune-competent and immunocompromised subjects. ${ }^{18-23}$ In Congenital CMV infection, there is strain diversity and infection with multiple CMV strains occurs in congenital CMV infection. Neither, the pathogenesis nor the long-term effect of specific or co-infecting genotypes is currently known. ${ }^{24} \mathrm{CMV}$ genome is composed of linear, double-stranded DNA, surrounded by a matrix protein lining containing phosphoproteins, which causes the dysregulation of the host's cell cycle. The protein lining is enveloped by several glycoproteins that are necessary for the virus's infectivity, including entrance to the host cell, cell-to-cell dissemination and maturation. ${ }^{25}$ The fusion between the virus and the cell is mediated by the viral glycoprotein, ${ }^{25,26}$ which is followed by the entrance of the nucleocapsid and protein lining of the host cell cytoplasm. The nuclei are translocated, an infection marker that may be detected in serum within an hour. Many host cells act as the main reservoirs of $\mathrm{CMV}$, which includes the monocytes, fibroblasts, myeloid cells, epithelial and endothelial cells. ${ }^{25}$ Endothelial cells and macrophages play an important role in latency and seem to be critical for maintaining CMV in the host. ${ }^{27}$ After cell infection, viral replication begins within 12-24 hours, with the cytopathic effect seen in-vitro after 7-14 days. ${ }^{28}$ Through inhibiting RNA formation, CMV has the ability of thwarting its host's immune response, by preventing antigen presentation mechanism and blocking apoptosis. ${ }^{21}$ These mechanisms may lead to reactivation of a latent infection, often seen in transplant patients. ${ }^{29}$ Currently, there are three forms of active CMV infection: a) primary infection, when the virus infects a CMV-naive subject; b) endogenous infection in CMV- seropositive individuals who undergo reactivation from latency, and c) exogenous reinfection in previously infected individuals who acquire infection by a different strain. ${ }^{30}$ Either active or latent CMV infection induces sustained systemic inflammatory responses that are accompanied by a type 1 cytokine signature. ${ }^{31}$ Viral persistence is established in all infected individuals and is chronically productive or occurs as a latent infection in which viral gene expression is limited. ${ }^{3} \mathrm{CMV}$ reactivation can also occur as a result of elevated Tumor necrosis factor $(\mathrm{TNF}-\alpha){ }^{32}$ Furthermore, CMV reactivation through cyclicAMP also occurs as a result of proinflammatory prostaglandins and/ or stress catecholamine's stimulation. ${ }^{33,34}$ Cells of the myeloid lineage are also potent carriers of latent $\mathrm{CMV} .{ }^{35,36} \mathrm{CMV}$ can reactivate from latency by allogeneic stimulation of monocytes from seropositive donors. ${ }^{37}$

\section{EBV Co-infection}

Both CMV and Epstein-Barr virus (EBV) infection causes infectious mononucleosis (IM) characterized by fever, pharyngitis and lymphadenopathy. ${ }^{1}$ Each virus shares the ability to persist in latent form after primary infection ${ }^{1,38}$ with the ability to reactivation 
later under immunosuppression conditions. EBV is the most common cause of IM, but primary CMV infection will cause up to $7 \%$ of IM cases with almost indistinguishable symptoms. ${ }^{39}$ Co-infection with CMV and EBV occurs occasionally in children. ${ }^{40,41}$ EBV/CMV can infect immuno competent patients simultaneously with other agents including respiratory syncytial virus (RSV), Chlamydia pneumonia (CP), human herpes virus 6 or 7, measles virus and others [40,42-46], and it has been reported that EBV/CMV- immune-competent infected children suffers from mixed infections with other agents. ${ }^{44,46}$

Children who show both EBV and CMV primary infection are typically presented with the typical manifestations of IM together with high occurrence of hepatomegaly $(57.1 \%)$, splenomegaly $(57.1 \%)$ and liver function abnormalities $(80.0 \%)$. The co-infection rate with other pathogens is high as $100 \%$, and the prevalence of multi-pathogen infection is $80 \%$, which is higher than that of the children with a single EBV or CMV infection. ${ }^{47} \mathrm{EBV}$ and CMV coinfection could have synergistic influence on allergen-specific B-cell responses and NK-cell cytokine production. ${ }^{48,49}$ EBV and CMV coinfection in children also increases the frequencies of differentiated $\mathrm{NKG}_{2} \mathrm{C}^{+}$and $\mathrm{CD} 57^{+} \mathrm{NKG} 2 \mathrm{C}^{+}$NK-cell subsets through unknown mechanism. Weather EBV and CMV co-infection leads to a more pathological consequences or synergetic effect on the subject long term heath, remains to be elucidated Research on multiple infections accompanying EBV/CMV infection is relatively rare, and warrant more extensive immunological investigations.

\section{CMV co-infection with upper respiratory tract viruses}

Common RNA and DNA viruses' that usually causes self-limited upper respiratory tract infections in immuno competent adults is known as Community respiratory viruses (CRV). ${ }^{50}$ However, CRV infections in the immunocompromised patient, often involves the lower respiratory tract and are associated with significant morbidity and mortality. ${ }^{51}$ The immunopathological mechanisms of respiratory viral infections remain to be investigated. In normal hosts, Paramyxoviruses (RSV) primarily infect airway epithelial cells, with subsequent immune responses that may lead to either resolution or chronic airways disease. ${ }^{52} \mathrm{RSV}$ infection of respiratory epithelial cells induces toll-like receptor (TLR4), which is a potent activator of T-helper 1 (Th1), which leads to interferon- $\gamma($ IFN- $\gamma)$, tumor necrosis factor- $\alpha$ (TNF- $\alpha$ ), and interleukin-2 (IL-2) production, as well as cytolytic $\mathrm{T}$ cell responses that are responsible for the resolution of the infection. ${ }^{53}$ Influenza viruses infection result in a toll-like receptor 3 (TLR3) mediated innate immune response, activation of $\mathrm{CD}^{+}$, and induction of IFN- $\gamma$ and TNF- $\alpha .{ }^{54}$ Regulation of this response to limit lung injury is complex due to the attenuation of lung inflammation that is dependent on IL-10 production by $\mathrm{CD} 8^{+} \mathrm{T}$ lymphocytes, or development of a protective Th17 response in IL10 deficient hosts that enhances survival after influenza infection. ${ }^{55,56}$ The immunopathogenesis of CMV infection is highly complex as it engages both the innate and adaptive immunity, in addition to humoral immunity from B cells and plasma cells. ${ }^{56}$ In immunocompromised patients or lung transplant recipient, where immunosuppression is intense will limit the memory $\mathrm{T}$ cell immune responses that are important for optimal CMV immune control..$^{57}$ Investigational studies of CMV and other upper respiratory virus's co-infection are rare, and warrant more studies.

\section{CMV/HHV6, 7 Co-infection}

Human herpesvirus6 (HHV-6) is a frequently detectable pathogen after transplantation, ${ }^{58,59}$ and is considered as a cofactor for increased
CMV replication in the blood. ${ }^{60}$ HHV-6 DNA is detected in the epithelial lining fluid (BAL) of the lung transplant recipient (LTRs) at lower frequencies and concentrations than CMV or EBV and only in a limited part of the samples in co-infection with the other herpes viruses. But so far a possible pathogenic role of HHV-6 or CMV/HHV6 co-infection in LTRs is unknown. ${ }^{61}$ Active co-infection with CMV and HHV-7 in immunocompetent patients resulted in the development of encephaloradiculomyelitis, indicating infection of the central and peripheral nervous systems, caused by CMV and HHV7.62 Such viral co-infection has only been described in immunocompromised patients with CMV disease, in which HHV-7 was presumed to be to a cofactor, enhancing clinical manifestations. The actual immunopathological mechanisms involved are unknown. ${ }^{63}$ Primary infection is uncommon in solid organ transplant adult recipients, but reactivation of endogenous latent viruses occur very frequently. ${ }^{64}$ The indirect effect of these viruses appears to be an interaction with CMV that may promote replication and persistence of the latter virus. ${ }^{65}$ The cause of such interactions is unknown, but may be due to cytokine dysregulation induced by viral gene products or due to more direct effects of viral co-infection within a single cell. ${ }^{64}$

\section{CMV/HSV Co-infection}

The majority of infections with herpes simplex virus (HSV) and CMV are clinically mild or even asymptomatic, primary infection in the fetal and perinatal periods can be neurologically devastating or fatal. ${ }^{66} \mathrm{HSV}$ generally infects a limited number of cell types, including mucosal and cutaneous epithelial cells and neurons, and may be clinically silent or cause ulcerative lesions. Spread of the virus to other tissues is associated with an inability of the immune system to limit viral replication to the mucosa, and latent infection is largely restricted to neurons. ${ }^{67}$ While CMV and HSV infections were critically reviewed, no data are available for the $\mathrm{CMV} / \mathrm{HSV}$ co-infections. ${ }^{68}$

\section{CMV/TB Co-infection}

Mycobacterium tuberculosis (TB) infection is second to HIV as an infectious cause of death globally and is still one of the life-threatening infections worldwide among renal transplants, because of their chronic immunosuppression, often with delayed diagnosis. ${ }^{69-71}$ The incidence of both multidrug-resistant and extensively drug-resistant TB continues to rise. ${ }^{72}$ Inhalation of infectious droplets expectorated by a patient with active pulmonary disease starts the life cycle of TB. The immune response to TB infection is mainly based on the matrix metalloproteinases (MMP) derived from the monocytes and leukocytes (infected or influxed to the lungs). Despite the wide spread of CMV infections and its hampering consequences of the immune system, little work has been done to identify the immunopathological relation in CMV and TB co-infection. Some TB patients will develop TB meningitis (TBM). The immune response within the brain is poorly understood or explored..$^{73}$ In TBM, CSF shows increased levels of inflammatory mediators, including TNF, IFN-g, IL-8, IL10 , MMPs, and their corresponding tissue inhibitors, the exact role of those cytokines remains to be clarified. TB is more common in allograft recipients than the general population. CMV infection is common post transplantation, and may predispose the patients to secondary bacterial or fungal infections. However, simultaneous co-infection is rare in allograft recipients and often makes diagnosis difficult. $^{74,75}$

\section{CMV/HCV Co-infection}

Chronic hepatitis $\mathrm{C}$ virus (HCV) infection leads to exhaustion and 
death of HCV-specific T-cells, but also causes defects in the overall immune defense. ${ }^{76}$ This notion is supported of by the fact that peripheral dendritic and naive $\mathrm{CD}^{+} \mathrm{T}$-cells are reduced both in number and function in individuals with chronic $\mathrm{HCV},{ }^{77,78}$ Peripheral $\mathrm{CD}^{+}{ }^{+} \mathrm{T}-\mathrm{cell}$ numbers are also reduced in patients with $\mathrm{HCV}$-associated cirrhosis. Therefore, chronic HCV infection will affect the immune response against CMV in a similar fashion to that seen withhold age and HIV infection. ${ }^{79}$ In liver transplant patients and those receiving $\mathrm{HCV}$ antiviral therapy the association of HCV with CMV pathogenesis is documented. ${ }^{80,81}$ Post-transplantation, CMV is well documented to be a potential threat to renal transplant recipients and is a significant cause of morbidity and mortality. ${ }^{82,83}$ Also, it is well established that CMV infection facilitates renal allograft rejection and may result in a varied spectrum of diseases ranging from respiratory tract to gastrointestinal diseases, retinitis, myelosuppression and neurological involvement75. In addition, CMV pneumonitis in renal transplant patients is a well-known complication with high mortality and morbidity rates. ${ }^{84}$ Immune suppression and aggravation of other viral diseases is a consequence of CMV infection. CMV infection enhances $\mathrm{HCV}$ pathogenesis by preventing the normal mechanisms responsible for HCV clearance, thus playing vital role in HCV persistence and pathogenicity. ${ }^{85}$

\section{CMVIHIV Co-infection}

CMV and human immunodeficiency virus (HIV) share common features, including route of transmission, immunosuppression, and the negative impact on the immune system. ${ }^{1}$ Co-infection with both viruses is common, with serious complications. The genito-urinary tract is known to support both HIV and CMV replication. ${ }^{86}$ Levels of CMV DNA in semen are correlated with the number and activation state of CD4 ${ }^{+}$T-lymphocytes found in the same compartment. ${ }^{87} \mathrm{CMV}$ DNA viral load detected in semen correlates positively with the semen HIV-1 viral load. CMV replication in the male genital tract may lead to local immune activation and enhanced HIV-1 replication. Therefore, the connections between CMV and HIV-1 are likely important. ${ }^{88}$ In CMV infected patients, there is an increased CMV-specific $\mathrm{CD}^{+} \mathrm{T}$-cell responses once HIV infection has been established, even before the loss of peripheral $\mathrm{CD}^{+} \mathrm{T}$ cells ${ }^{89,90} \mathrm{CMV}$ also induces a proinflammatory state in the genital tract that activates HIV-1 and that anti retrovirus therapy (ART) does not have an impact on this interaction. ${ }^{91} \mathrm{CMV}$ IgG may be associated with increased carotid artery stiffness and carotid artery lesions in HIV-infected women, with those on effective antiretroviral therapy may be at higher risk to develop vascular lesions in association with CMV coinfection..$^{92} \mathrm{CMV}$ co-infection is highly prevalent in $\mathrm{HIV}^{+}$patients at a rate of $75 \%$ and $90 \% .{ }^{93,94}$ Unfortunately; many areas of HIV research have not taken in consideration the effect or the impact of CMV co-infection on the immunopathology of HIV infection as evident in the literature.

\section{CMVIOther Pathogen Co-infection}

CMV co-infections with other pathogens or in association with other inflammatory disorders is poorly understood, as most of the information available relied on case reports or smaller studies. ${ }^{95,96}$

\section{Conclusion}

The strength of the humoral and cellular immune responses depends on interaction of viruses that are present during co-infections of the host. CMV is one of the most prevalent infectious viruses worldwide, which infects a wide range of cell types and establishes a life-long, persistent infection. CMV infection, latent or active is a major health risk with huge public health burden. The lack of current treatment and reliable vaccine highlight the urgent need to focus more research resources, and emphasis the importance of considering CMV status in clinical assessment. The pathophysiological and immunopathological effects of CMV co-infections are still to a large extent speculative especially with the emerging new viruses. Additional research is need because CMV co-infections increase the morbidity and mortality of patients.

Most of the work done to date, did not take in account the effect of the genetic makeup of the hosts in relation to the different virus stains. We are not aware of any laboratory studies that addressed the CMV co-infection and established the relationship between CMV and other pathogen infections. Future efforts are needed to explain and characterize the pathological effects of CMV co-infection. Whether CMV would change, inhibit, or promote the other pathogen course of infection, is the current question to be answered, as it will have many implications on the patient treatment and outcomes. With the advances in anti-viral technology and genetics, future efforts should be directed toward the eradication of the silent viruses such as CMV or EBV.

\section{Acknowledgements}

None.

\section{Conflicts of Interest}

There is no conflict of interest.

\section{Funding}

None.

\section{References}

1. Mocarski ES, Shenk T, Pass RF. Cytomegaloviruses. In: Knipe DM, Howley PM, Griffin DE, Lamb RA, Martin MA, et al. (Eds.), Fields virology $\left(5^{\text {st }}\right.$ edn), Lippincott Williams and Wilkins, USA. 2007;2: pp.2701-2773.

2. Novak Z, Ross SA, Patro RK, et al. Cytomegalovirus strain diversity in seropositive women. J Clin Microbiol. 2008;46(30): 882-886.

3. Britt W. Manifestations of human cytomegalovirus infection: proposed mechanisms of acute and chronic disease. Curr Top Microbiol Immunol. 2008;325:417-470.

4. Stefania V, Maria PL. Cytomegalovirus-induced immunopathology and its clinical consequences. Herpesviridae. 2011;2: 6.

5. Powers $\mathrm{C}$, Fruh K. Rhesus CMV: an emerging animal model for human CMV. Med Microbiol Immunol. 2008;197(2):109-115.

6. Nichols WG, Boeckh M. Recent advances in the therapy and prevention of CMV infections. J Clin Virol. 2000;16(1):25-40.

7. Vaccines for the 21 st Century Stratton KR, Durch JS, Lawrence RS. Editors, DC: National Academy Press, Washington, USA. 2000.

8. Sylwester AW, Mitchell BL, Edgar JB, et al. Broadly targeted human cytomegalovirus-specific $\mathrm{CD}^{+}$and $\mathrm{CD}^{+} \mathrm{T}$ cells dominate the memory compartments of exposed subjects. J Exp Med. 2005;202(5):673-685.

9. Soderberg-Naucler C, Nelson JY. Human cytomegalovirus latency and reactivation - a delicate balance between the virus and its host's immune system. Intervirology. 1999;42(5-6):314-321.

10. Huff JL, Eberle R, Capitanio J, et al. Differential detection of B virus and rhesus cytomegalovirus in rhesus macaques. J Gen Virol. 2003;84(Pt 1):83-92. 
11. Reinke P, Prosch S, Kern F, et al. Mechanisms of human cytomegalovirus (HCMV) (re)activation and its impact on organ transplant patients. Transpl Infect Dis. 1999;1(3):157-164.

12. Simon CO, Holtappels R, Tervo HM, et al. CD8 T cells control cytomegalovirus latencyby epitope-specific sensing of transcriptional reactivation. J Virol. 2006;80(21):10436-10456.

13. Streblow DN, Orloff SL, Nelson JA. Do pathogens accelerate atherosclerosis? J Nutr. 2001;131(10):2798S-2804S.

14. Murphy E, Shenk T. Human cytomegalovirus genome. Curr Top Microbiol Immunol. 2008;325:1-19.

15. Murphy E, Yu D, Grimwood J, et al. Coding potential of laboratory and clinical strains of human cytomegalovirus. Proc Natl Acad Sci U S A. 2003;100(25):14976-14981

16. Dunn W, Chou C, Li H, et al. Functional profiling of a human cytomegalovirus genome.Proc NatlAcad SciUSA. 2003;100(24):1422314228.

17. Miller-Kittrell M, Sparer TE. Feeling manipulated: cytomegalovirus immune manipulation. Virol J. 2009;6:4.

18. Bale JF Jr, Petheram SJ, Souza IE, et al. Cytomegalovirus reinfection in young children. J Pediatr. 1996;128(3):347-352.

19. Coaquette A, Bourgeois A, Dirand C, et al. Mixed cytomegalovirus glycoprotein B genotypes in immunocompromised patients. Clin Infect Dis. 2004;39(2):155-161.

20. Gorzer I, Kerschner H, Jaksch P, et al. Virus load dynamics of individual CMV-genotypes in lung transplant recipients with mixed-genotype infections. J Med Virol. 2008;80:1405-1414.

21. Smith W, Tomasec P, Aicheler R, et al. Human cytomegalovirus glycoprotein UL141 targets the TRAIL death receptors to thwart host innate antiviral defenses. Cell Host Microbe. 2013;13(3):324-335.

22. Noriega VM, Haye KK, Kraus TA, Kowalsky SR, Ge Y, et al. Human cytomegalovirus modulates monocyte-mediated innate immune responses during short-term experimental latency in vitro. J Virol. 2014;88(16):9391-9405.

23. Reeves M, Sinclair J. Aspects of human cytomegalovirus latency and reactivation. Curr Top Microbiol Immunol. 2008; 325: 297-313.

24. Ross SA, Novak Z, Pati S, et al. Mixed infection and strain diversity in congenital cytomegalovirus infection. J Infect Dis. 2011;204:10031007

25. Stern JL, Slobedman B. Human cytomegalovirus latent infection of myeloid cells directs monocyte migration by up-regulating monocyte chemotactic protein-1. J Immunol. 2008;180(10):6577-6585.

26. Slobedman B, Cheung AK. Microarrays for the study of viral gene expression during human cytomegalovirus latent infection. Methods Mol Med. 2008;141:153-175.

27. Sinzger C, Jahn G. Human cytomegalovirus cell tropism and pathogenesis. Intervirology. 1996;39(5-6):302-319.

28. Jarvis MA, Nelson JA. Human CMV persistence and latency in endothelial cells and macrophages. Curr Opin Microbiol. 2002;5(4): 403-407.

29. Rowshani AT, Bemelman FJ, van Leeuwen EM, et al. Clinical and immunologic aspects of CMV infection in solid organ transplant recipients. Transplantation. 2005;79(4):381-386.

30. Rubin RH. The pathogenesis and clinical management of cytomegalovirus infection in the organ transplant recipient: the end of the 'silo hypotheses'. Curr Opin Infect Dis. 2007;20(4):399-407.

31. van de Berg PJ, Heutinck KM, Raabe R, et al. Human cytomegalovirus induces systemic immune activation characterized by a type 1 cytokine signature. J Infect Dis. 2010;202(5):690-699.
32. Docke WD, Kiessling C, Worm M, et al. Subclinical activation of latent cytomegalovirus (CMV) infection and anti-CMV immune response in patients with atopic dermatitis. Br J Dermatol. 2003;148(5):954-963.

33. Kline JN, Hunninghake GM, He B, et al. Synergistic activation of the human cytomegalovirus major immediate early promoter by prostaglandin E2 and cytokines. Exp Lung Res. 1998;24(1):3-14.

34. Prosch S, Wendt CE, Reinke P, et al. A novel link between stress and human cytomegalovirus (HCMV) infection: sympathetic hyperactivity stimulates HCMV activation. Virology. 2000;272(2):357-365.

35. Mendelson M, Monard S, Sissons P, et al. Detection of endogenous human cytomegalovirus in $\mathrm{CD}_{3} 4^{+}$bone marrow progenitors. J Gen Virol. 1996;77(Pt 12):3099-3102.

36. Soderberg-Naucler C, Fish KN, et al. Reactivation of latent human cytomegalovirus by allogeneic stimulation of blood cells from healthy donors. Cell. 1997;91(1):119-126.

37. Reeves MB, MacAry PA, Lehner PJ, et al. Latency, chromatin remodeling, and reactivation of human cytomegalovirus in the dendritic cells of healthy carriers. Proc Natl Acad Sci USA. 2005;102(11):41404145 .

38. Cohen JI. Epstein-Barr virus infection. N Engl J Med. 2000;343(7):481492.

39. Taylor GH. Cytomegalovirus. Am Fam Physician. 2003;67(3):519-524.

40. Alvarez-Lafuente R, Aguilera B, Suarez-Mier MA, et al. Detection of human herpesvirus-6, Epstein-Barr virus and cytomegalovirus in formalin-fixed tissues from sudden infant death: a study with quantitative real-time PCR. Forensic Sci Int. 2008;178(2-3):106-111.

41. Ito Y, Shibata-Watanabe Y, Kawada J, et al. Cytomegalovirus and Epstein-Barr virus coinfection in three toddlers with prolonged illnesses. J Med Virol. 2009;81(8):1399-1402.

42. Abughali N, Khiyami A, Birnkrant DJ, et al. Severe respiratory syncytial virus pneumonia associated with primary Epstein-Barr virus infection. Pediatr Pulmonol. 2002;33(5):395-398.

43. Van der Laan NE, Voerman BJ, Rustemeijer C, et al. Peritonitis, moderate ascites and hepatitis due to infection with Chlamydia trachomatis and Epstein-Barr virus in a young woman. Diagnosis by polymerase chain reaction from peritoneal tissue. Neth J Med. 1995;46(1):41-43.

44. Mehraein Y, Lennerz C, Ehlhardt S, et al. Replicative multivirus infection with cytomegalovirus, herpes simplex virus 1 and parvovirus B19 and latent Epstein-Barr virus infection in the synovial tissue of a psoriatic arthritis patient. J ClinVirol. 2004;31(1):25-31.

45. Atrasheuskaya AV, Kameneva SN, Neverov AA, et al. Acute infectious mononucleosis and coincidental measles virus infection. J Clin Virol. 2004;31:160-164.

46. Peng D, Zhao D, Liu J, et al. Multipathogen infections in hospitalized children with acute respiratory infections. Virol J. 2009;6:155.

47. Wang X, Yang K, Wei C, et al. Coinfection with EBV/CMV and other respiratory agents in children with suspected infectious mononucleosis. Virology J. 2010;7:247.

48. Nilsson C, Linde A, Montgomery SM, et al. Does early EBV infection protect against IgE sensitization? J Allergy Clin Immunol. $2005 ; 116(2): 438-444$

49. Saghafian-Hedengren S, Sundstrom Y, Sohlberg E, et al. Herpes virus seropositivity in childhood associates with decreased monocyte induced NK cell IFN-gamma production. J Immunol. 2009;182:2511-2517.

50. Shah PD, McDyer JF. Viral infections in lung transplant recipients. Semin Respir Crit Care Med. 2010;31(2):243-254.

51. Kim YJ, Boeckh M, Englund JA. Community respiratory virus infections in immunocompromised patients: hematopoietic stem cell and solid organ transplant recipients, and individuals with human immunodeficiency virus infection. Semin Respir Crit Care Med. 2007;28(2):222-242. 
52. Mahalingam S, Schwarze J, Zaid A, et al. Perspective on the host response to human metapneumovirus infection: what can we learn from respiratory syncytial virus infections? Microbes Infect. 2006;8(1):285-293.

53. Delgado MF, Coviello S, Monsalvo AC, et al. Lack of antibody affinity maturation due to poor Toll-like receptor stimulation leads to enhanced respiratory syncytial virus disease. Nat Med. 2009;15(1):34 41.

54. Le Goffic R, Pothlichet J, Vitour D, et al. Cutting edge: influenza A virus activates TLR3-dependent inflammatory and RIG-I-dependent antivira responses in human lung epithelial cells. J Immunol. 2007;178(6):33683372 .

55. Fishman JA, Rubin RH. Infection in organ-transplant recipients. $N$ Engl J Med. 1998;338:1741-1751.

56. Taylor DO, Edwards LB, Boucek MM, et al. Registry of the International Society for Heart and Lung Transplantation: twenty-fourth official adult heart transplant report-2007. J Heart LungTransplant. 2007;26(8):769781.

57. Gerna G, Lilleri D, Rognoni V, et al. Preemptive therapy for systemic and pulmonary human cytomegalovirus infection in lung transplant recipients. Am J Transplant. 2009;9(5):1142-1150.

58. Jacobs F, Knoop C, Brancart F, et al. Human herpesvirus-6 infection after lung and heart-lung transplantation: a prospective longitudinal study. Transplantation. 2003;75(12):1996-2001.

59. Neurohr C, Huppmann P, Leuchte H, et al. Human herpesvirus 6 in bronchalveolar lavage fluid after lung transplantation: a risk factor for bronchiolitis obliterans syndrome? Am J Transplant. 2005;5(12):29822991.

60. Campadelli-Fiume G, Mirandola P, Menotti L. Human herpesvirus 6: an emerging pathogen. Emerg Infect Dis. 1999;5(3):353-366.

61. Bauer CC, Jaksch P, Aberle SW, et al. Relationship between cytomegalovirus DNA load in epithelial lining fluid and plasma of lung transplant recipients and analysis of coinfection with Epstein-Barr virus and human herpesvirus 6 in the lung compartment. J Clin Microbiol. 2007;45(2):324-328.

62. Ginanneschi F, Donati D, Moschettini D, et al. Encephaloradiculomyelitis associated to HHV-7 and CMV co-infection in immunocompetent host. Clin Neuro and Neurosurg. 2007;109(3):272-276.

63. Nakamichi $\mathrm{K}$, Inoue $\mathrm{N}$, Shimokawa $\mathrm{T}$, et al. Detection of human herpesviruses in the cerebrospinal fluid from patients diagnosed with or suspected of having progressive multifocal leukoencephalopathy. BMC Neurology. 2013;13:200.

64. Mendez JC, Dockrell DH, Espy MJ, et al. Human beta-herpesvirus interactions in solid organ transplant recipients. $J$ Infect Dis. 2001;183(2):179-184

65. Other herpesviruses: HHV-6, HHV-7, HHV-8, HSV-1 and -2, VZV Am J Transplant. 4(Suppl 10): 66-71.

66. Crumpacker CS, Wadhwa S, Cytomegalovirus. In: Mandell GL, Bennett JE, Dolin R (Eds.), Principles and Practice of Infectious Diseases (6th edn). Churchill Livingstone, Philadelphia, USA. 2005

67. Roizman B, Knipe D, Whitley R. Herpes Simplex Viruses. In: Knipe D, Howley P. Editors. Fields Virology. 5th edition Lippincott Williams \& Wilkins, Philadelphia, USA. 2007.

68. Muller WJ, Jones CA, Koelle DM. Immunobiology of herpes simplex virus and cytomegalovirus infections of the fetus and newborn. Curr Immunol Rev. 2010;6(1):38-55.

69. John GT, Shankar V. Mycobacterial infections in organ transplant recipients. Semin Respir Infect. 2002;17(4):274-283.
70. Horne DJ, Narita M, Spitters CL, et al. Challenging issues in tuberculosis in solid organ transplantation. Clin Infect Dis. 2013;57(10):1473-1482.

71. Meije Y, Piersimoni C, Torre-Cisneros J, et al. Mycobacterial infections in solid organ transplant recipients. Clin Microbiol Infect. 2014.

72. Raviglione MC, Smith IM. XDR tuberculosis-implications for global public health. $N$ Engl J Med. 2007;356(7):656-659.

73. Elkington PT, Ugarte-Gil CA, Friedland JS. Matrix metalloproteinases in tuberculosis. Eur Respir J. 2011;38(2):456-464.

74. Nafar M, Firouzan A, Einollahi B. Miliary tuberculosis and CMV infection in a kidney recipient. Int J Nephrol Urol. 2009;1(2): 153-155.

75. Poulin S, Corbeil C, Nguyen M, et al. Fatal Mycobacterium colombiense / cytomegalovirus coinfection associated with acquired immunodeficiency due to autoantibodies against interferon gamma: a case report. BMC Infectious Diseases. 2013;13:24.

76. Thimme R, Binder M, Bartenschlager R. Failure of innate and adaptive immune responses in controlling hepatitis $\mathrm{C}$ virus infection. FEMS Microbiol Rev. 2011;36(3):663-683.

77. Ryan EJ, O'Farrelly C. The affect of chronic hepatitis C infection on dendritic cell function: a summary of the experimental evidence. $J$ Viral Hepat. 2011;18(9):601-607.

78. Yonkers NL, Sieg S, Rodriguez B, et al. Reduced naive CD4 T cell numbers and impaired induction of CD27 in response to $\mathrm{T}$ cell receptor stimulation reflect a state of immune activation in chronic hepatitis $\mathrm{C}$ virus infection. J Infect Dis. 2011;203(5):635-645.

79. Kuniholm MH, Parrinello CM, Anastos $\mathrm{K}$, et al. Hepatitis C viremia is associated with cytomegalovirus IgG antibody levels in HIV-infected women. PLoS One. 2013;8(4):e61973.

80. Razonable RR. Cytomegalovirus infection after liver transplantation: current concepts and challenges. World $J$ Gastroenterol. 2008;14(31):4849-4860.

81. Bader el-Din NG, Abd el-Meguid M, Tabll AA, et al. Human cytomegalovirus infection inhibits response of chronic hepatitis-Cvirus-infected patients to interferon-based therapy. $J$ Gastroenterol Hepatol. 2011;26(1):55-62.

82. Smith SR, Butterly DW, Alexander BD, et al. Viral infections after renal transplantation. Am J Kidney Dis. 2001;37(4):659-676.

83. Kotton CN, Fishman JA. Viral infection in the renal transplant recipient. J Am Soc Nephrol. 2005;16(6):1758-1774.

84. Stoffel M, Pirson Y, Squifflet JP, et al. Treatment of cytomegalovirus pneumonitis with ganciclovir in renal transplantation. Transplant Int. 1988;1(4):181-185

85. Chakraborty A, Patil K, Dasgupta S, et al. Incidence of CMV-HCV coinfection in renal transplant recipient. BMJ Case Reports. 2012.

86. Gianella S, Mehta SR, Strain MC, et al. Impact of seminal cytomegalovirus replication on hiv-1 dynamics between blood and semen. Med Virol. 2012;84(11):1703-1709.

87. Gianella S, Strain MC, Rought SE, et al. Associations between the virologic and immunologic dynamics in blood and in the male genital tract. J Virol. 2012b;86(3):1307-1315.

88. Appay V, Fastenackels S, Katlama C, et al. Old age and anti-CMY immunity are associated with altered $\mathrm{T}$ cell reconstitution in HIV-1 infected patients. AIDS. 2011;25(15):1813-1822.

89. Naeger DM, Martin JN, Sinclair E, et al. Cytomegalovirus-specific T cells persist at very high levels during long-term antiretroviral treatment of HIV disease. PLoS One. 2010;59(1):e8886.

90. Lurain NS, Robert ES, Xu J, et al. HIV type 1 and cytomegalovirus coinfection in the female genital tract. J Infect Dis. 2004;190(3):619623. 
91. Jackson JB, Erice A, Englund JA, et al. Prevalence of cytomegalovirus antibody in hemophiliacs and homosexuals infected with human immunodeficiency virus type 1. Transfusion. 1988;28(2):187-189.

92. Mintz L, Drew WL, Miner RC, et al. Cytomegalovirus infections in homosexual men. An epidemiological study. Ann Intern Med. 1983;99(3):326-329.

93. von Muller L, Klemm A, Weiss M, et al. Active cytomegalovirus infection in patients with septic shock. Emerq Infect Dis. 2006;12(10):1517-1522.

94. Jacobi CA, Riessen R, Schumacher U, et al. Life-threatening pneumonia caused by human cytomegalovirus and Mycoplasma pneumonia coinfection in a young, immunocompetent patient. J Med Microbiol. 2010;59(Pt 8):980-983.
95. Gayathri Devi HJ, Mahesh E, Kamath SM. Pulmonary mucormycosis and cytomegalovirus co-infection in a renal transplant recipient. J Case Reports. 2013;3(1):76-80.

96. Acar J, Torresa GR, Poti Salesb JW, et al. Pneumocystis jirovecii and cytomegalovirus co-infection in AIDS patients. $J$ Med Cases. 2013;4(6):402-406. 